\title{
Д.
}

\section{The effect of date marking terminology of products with a long shelf life on food discarding behaviour of consumers}

BO-projects 20-015-031 and 20-015-032

Nancy Holthuysen, Stefanie Kremer, Hilke Bos-Brouwers

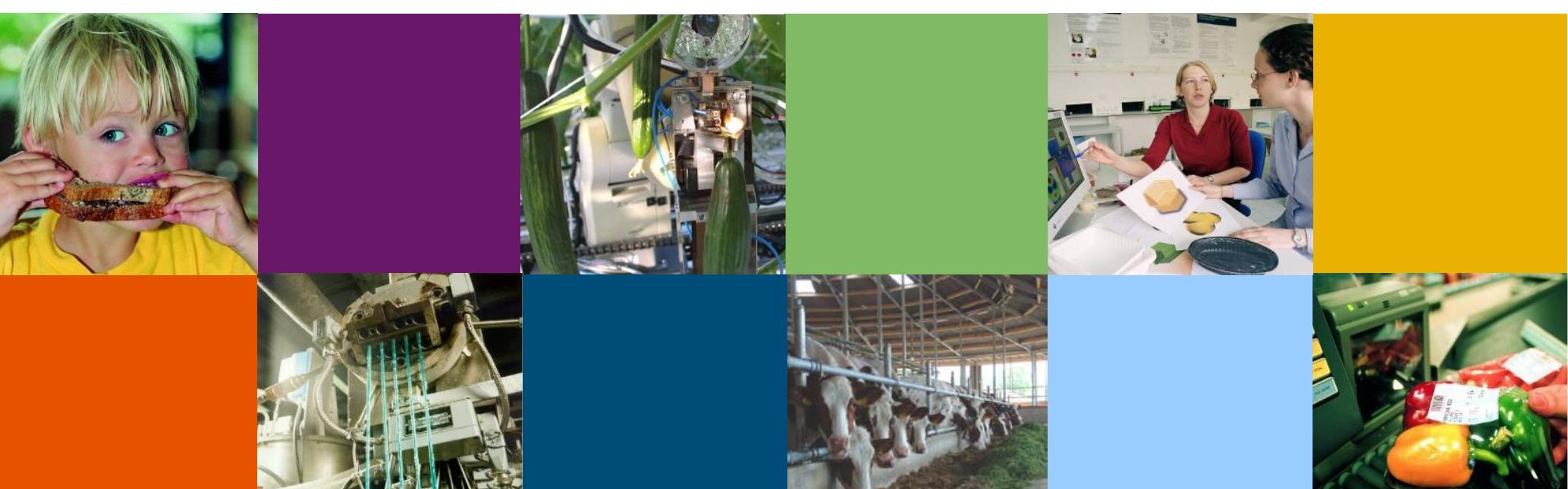




\section{Publication details}

Title The effect of date marking terminology of products with a long shelf life on the discarding behaviour of consumers [Effect van houdbaarheidsdata van lang houdbare producten op weggooigedrag van consumenten]

Author(s) Nancy Holthuysen, Stefanie Kremer, Hilke Bos-Brouwers

Number 1709

ISBN number 978-94-6343-229-0

DOI number https://doi.org/10.18174/428726

Publication date After approval Ministry of Economic Affairs - 27 March 2017

Version 1

Confidential No

OPD code $\mathrm{n} / \mathrm{a}$

Approved by Judith van der Horst

Review Internal

Name of reviewer Toine Timmermans

Financing party Ministry of Economic Affairs via BO research funds

Commissioning party Ministry of Economic Affairs - Department of Plant Supply Chain and Food Quality (Directie PAV)

Wageningen Food \& Biobased Research

P.O. Box 17

NL-6700 AA Wageningen

Tel: $+31(0) 317480084$

E-mail: info.fbr@wur.nl

Internet: www.wur.nl/foodandbiobased-research

(C) Wageningen Food \& Biobased Research, an institute within the legal entity Stichting Wageningen Research (Wageningen Research Foundation)

All rights reserved. No part of this publication may be reproduced, stored in a retrieval system of any nature, or transmitted, in any form or by any means, electronic, mechanical, photocopying, recording or otherwise, without the prior permission of the publisher. The publisher does not accept any liability for inaccuracies in this report.or by any means, electronic, mechanical, photocopying, recording or otherwise, without the prior permission of the publisher. The publisher does not accept any liability for inaccuracies in this report. 


\section{Summary}

Better understanding of consumer food waste behaviour is an important key to reducing food waste. Prior research, both national (e.g. Netherlands Nutrition Centre/GfK, 2013), and European (e.g. Flash Eurobarometer 425 on Food waste and date marking, 2015), indicates that misinterpretation of date marking by consumers is very often given as one of the more important causes of food waste. However, little is as yet known about the size of this effect and how the terminology used might affect this. As a result, the Ministry of Economic Affairs commissioned Wageningen Food \& Biobased Research to conduct a study on what the effects on consumer discarding behaviour are of using alternative terminology and omitting date marking on products with a long shelf life.

The main question is whether changing or omitting the date marking terminology currently being used (i.e. 'best before date') on products with a long shelf life could contribute to decreasing food waste by households. This qualitative study has been conducted in an experimental setting using sorting assignments, online visual surveys and focus group discussions conducted by a group of 86 Dutch consumers. The experiments were conducted in a controlled environment. No research was conducted into discarding behaviour based on the number of kilograms ending up in waste bins, but concerned the selection behaviour related to products that respondents would discard in the experimental setting.

The results provide new indicative insights into how changing date marking terminology - or its omission - could influence the prevalence of food waste. Products with a long shelf life here are taken to mean products which under current legislation must be labelled with a best before date (Dutch: THT datum, Tenminste Houdbaar Tot datum, i.e. 'can be preserved until at least date'). The study was restricted to a selection of these products, namely those which can be stored at ambient temperature. Examples of such products are rice, pasta, coffee and tinned soup.

This study indicates that respondents discard fewer products if there is no best before date on the packaging. On average, in this experiment 39\% of the products were thrown away if the best before date had expired. If there was no best before date on the packaging, $27 \%$ was thrown away. This is a difference of $12 \%$ on average. However, there are major differences between product categories.

The results with regard to using alternative terminology showed that respondents throw away $31 \%$ less if the term 'Long shelf life' is used on the packaging (without a specific date). Although respondents discarded less, they indicated that they were uncomfortable with this term. It does not provide any clarity concerning the food safety and quality of the product in question. This uncertainty turns out to have a significant influence on consumer discarding behaviour: Can I still safely consume this product? Will it taste good? 
The conclusion of this study is that both omitting date marking and introducing alternative terminology could contribute to decreasing food waste in households. Introducing these measures in stages is recommended, since the study indicated that for some of the product groups being investigated (products such as sugar, rice, flour and tea), respondents did not experience such uncertainty. Using the term 'long shelf life' on the packaging of these products seems promising. In addition, attention should be paid to changing the risk perception of consumers. There are various options, such as providing better consumer information, providing information on the product packaging (perhaps also with QR codes or smartphone applications). Further investigation will have to show how precisely this should be done. 


\section{Contents}

Summary 3

1 Introduction 6

2 Methodology 7

$\begin{array}{lll}2.1 & \text { Sorting task } & 7\end{array}$

$\begin{array}{lll}2.2 & \text { Online task } & 10\end{array}$

2.3 Focus group discussion 11

$\begin{array}{lll}2.4 & \text { Participants } & 11\end{array}$

2.5 Products 11

3 Results 13

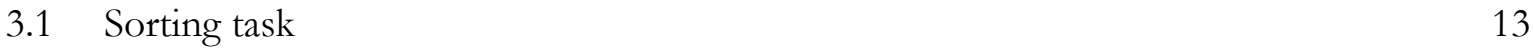

3.2 Online task 17

3.3 Focus group discussion 19

4 Discussion 21

5 Conclusions 22 


\section{Introduction}

Food waste is a major and complex problem in society. Estimates are that on a global basis, people do not consume about one third of the food produced (FAO, 2013) However, the exact amounts depend on the way in which this is measured and the definition of food waste being used. In Europe the estimates indicate about 88 Mton (edible and non-edible fractions) of food being wasted annually. This is approx.. $20 \%$ of total consumption. Data for the Netherlands indicate that in the entire food chain between 1.91 and 2.63 million tons are wasted, that is between 114-157 kg per person of (potentially) preventable food waste (Wageningen UR Food \& Biobased Research - Vollebregts et al. 2016). For a number of years, the amount of preventable food waste in households has been close to 50 kilograms per person per year (Netherlands Nutrition Centre, 2014). In 2009, the Dutch government committed itself to reducing food waste by $20 \%$ in 2015, and adopted the European Circular Economy Package published in December 2015. This states that the policy focus is achieving the United Nations Sustainable Development Goal (SDG) 12.3 by 2030 by halving food waste in the retail sector and by consumers, and reducing food loss earlier in the chain. Translating this challenge into concrete actions will thus have to take place in the coming period.

Better understanding consumer food waste behaviour is an important key to reducing food waste. Prior research, both national (e.g. Dutch Nutrition Centre, 2014) and European (e.g. Flash Eurobarometer 425 on Food waste and date marking, 2015), indicates that misinterpretation of date marking by consumers is very often given as one of the more important causes of food waste. However, little is yet known about the size of this effect and exactly what the influence of the terminology used is on this. As a result, the Ministry of Economic Affairs commissioned Wageningen Food \& Biobased Research to conduct a study into what the effects on consumer discarding behaviour are of using alternative terminology and omitting shelf life dating on products with a long shelf life.

The main question is whether changing or omitting the date marking terminology currently in use (i.e. best before date) on products with a long shelf life could contribute to reducing food waste by households. This initial qualitative study has been conducted in an experimental setting using sorting assignments, online visual surveys and focus group discussions conducted by a group of 86 Dutch consumers. The results provide new insights into how shelf life dating and terminology can influence the prevention of food waste.

The study was restricted to products with a long shelf life in sealed packaging. Here, products with a long shelf life refer to products which must carry a best before date on their packaging under current legislation. The study was restricted to a selection of these products, namely those that can be stored at ambient temperature. Examples of such products are rice, pasta, coffee and tinned soup.

6 (C) Wageningen Food \& Biobased Research, an institute within the legal entity Stichting Wageningen Research (Wageningen Research Foundation) 


\section{Methodology}

In order to answer the research question, an indicative consumer study was carried out, comprising three parts:

1. Sorting experiment in one of the research rooms at the Restaurant of the Future in Wageningen

2. Online study

3. Focus group discussions.

A diagram of the study design is depicted in Figure 1.

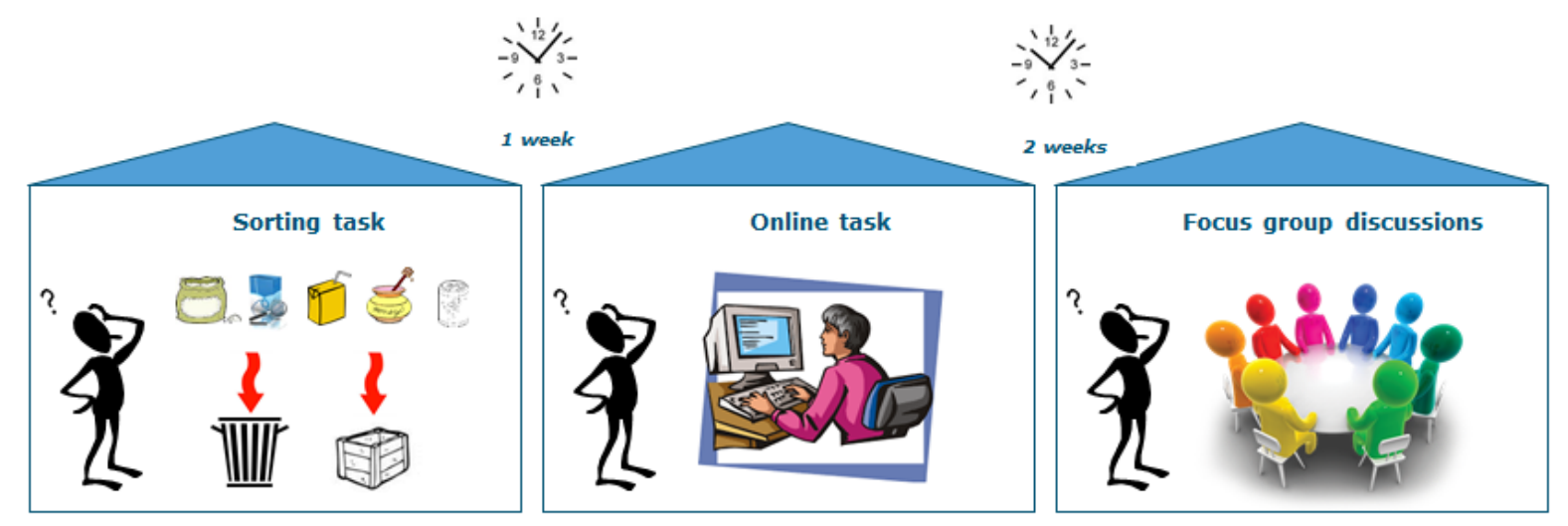

Figure 1. Study design

\subsection{Sorting task}

In the first part of the study the focus was on what the effect is if there is no date on the packaging.

The participants were given a brief 'cover story' before beginning the task. The aim of the cover story was to put the participants in a certain mind-set to be able to conduct the task in the proper manner. The various versions of the cover story can be found in Appendix 1. Depending on the age of the participant, a certain version of the cover story was selected.

The room that participants entered contained a cupboard with 60 products in it. The 60 products belonged to the 20 selected product categories (see Table 3), each with differing labels (design: 20 products $\mathrm{x} 3$ labels).

The labels on the packaging were:

- $\quad$ Product within best before date (25\% before best before date has expired)

- Product with expired best before date (25\% past the best before date)

- Product without a date. 
Three varieties of each product were used, for example orange juice, apple juice and tomato juice. The product presentation to participants was balanced but with differing information labels, that is each room contained all combinations equally often. An example can be found in Table 1. 
Table 1. Example of the product presentation for the sorting task

\begin{tabular}{lll}
\hline Room $\mathbf{1}$ & Room $\mathbf{2}$ & Room $\mathbf{3}$ \\
\hline $\begin{array}{l}\text { Orange juice within best } \\
\text { before date }\end{array}$ & $\begin{array}{l}\text { Orange juice after best } \\
\text { before date }\end{array}$ & Orange juice without date \\
$\begin{array}{ll}\text { Apple juice without date } \\
\text { Apple juice within best } \\
\text { before date }\end{array}$ & $\begin{array}{l}\text { Apple juice after best before } \\
\text { date }\end{array}$ \\
$\begin{array}{l}\text { Tomato juice after best } \\
\text { before date }\end{array}$ & $\begin{array}{l}\text { Tomato juice without best } \\
\text { before date }\end{array}$ & $\begin{array}{l}\text { Tomato juice within best } \\
\text { before date }\end{array}$ \\
\hline
\end{tabular}

Each participant visited one of the three rooms. The participants were asked to determine which of the 60 products in the cupboard they wanted to keep or throw away. They were expressly told that they could also keep the product to give to someone else (e.g. if it was a product they would never consume themselves because they disliked the taste). The participants were not allowed to open the packaging in determining what to do with it. Figure 2 shows participants engaged in the sorting task.
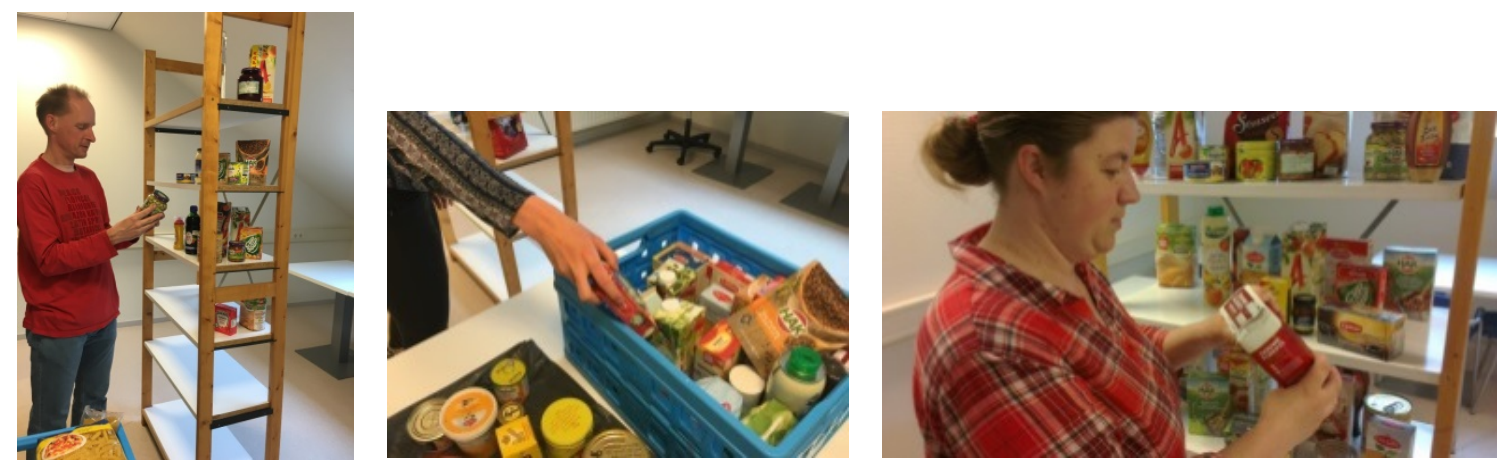

Figure 2. Participants during the sorting task 


\subsection{Online task}

The 10 products which were thrown away most often in the sorting task were selected for the online task (see Table 3). The focus of the online task was the effect of alternative terms on the discarding behaviour. In addition to the current term 'best before date', five alternative terms were investigated (see Table 2). The alternative terms used in this study were selected in consultation with the supervisory committee.

Table 2. List of the alternative terms

\begin{tabular}{l}
\hline Quality guaranteed until [date] \\
Inspect, smell and taste after [date] \\
At its best before [date] \\
Produced on [date] \\
Long shelf life \\
\hline
\end{tabular}

The participants were shown a picture of a product online accompanied by one of the alternative terms. In each instance they were asked whether they would keep the product or throw it away. All of the products used for the online task were $25 \%$ past their expiry date. In total participants judged 60 combinations each (design: 10 products $\times 6$ terms).

In order to keep the task enjoyable, within each product category six different variants were shown, for example tins of peas, string beans, carrots, maize, kidney beans and lentils.

Presentation among participants was balanced so that all terms and all variants were shown just as often. Figure 3 depicts an example of what participants were given as task.

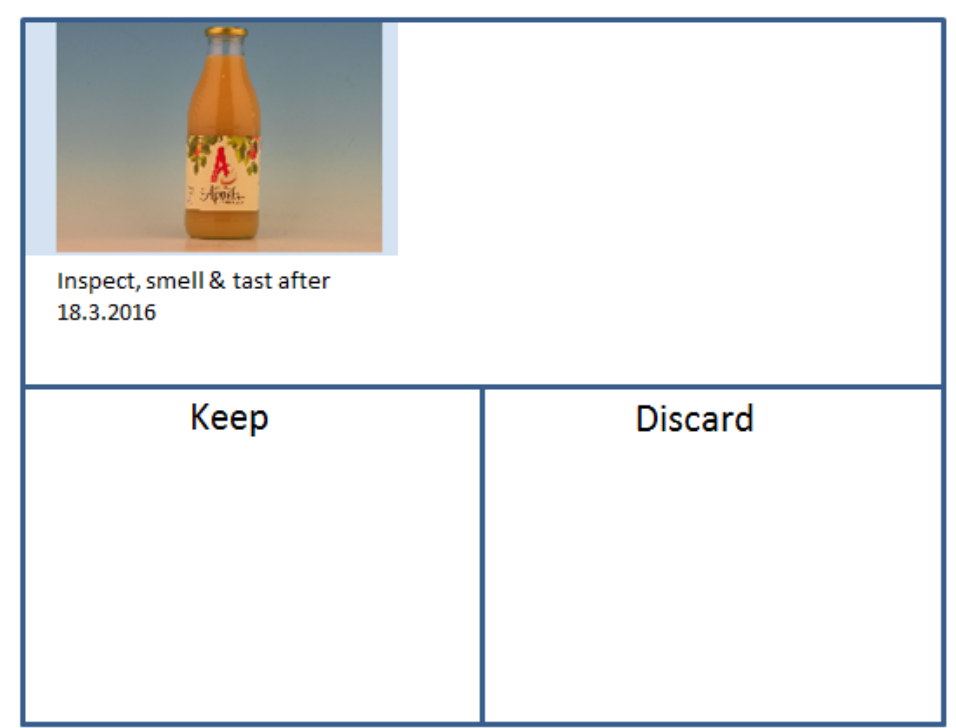

Figure 3. Assignment during the online task. Participants could drag products with their mouse to either the category keep or throw away. 


\subsection{Focus group discussion}

In order to gain greater insight into the motivations and backgrounds of the participants influencing why they made certain choices, focus group discussions were conducted. Two group discussions of 90 minutes each were conducted. The seven participants in the first group discussion were the individuals who had thrown away the most in the sorting task. The eight participants in the second group discussion were the individuals who had responded the most strongly to the alternative terms in the online task (either positively or negatively).

\subsection{Participants}

There were 86 participants in this study. Individuals were not selected to participate if they indicated that they never discarded products with a long shelf life. The participants were recruited via the Wageningen Food \& Biobased Research database and received an expense allowance of $€ 15$ for participating. The 15 participants in the focus group discussions received an additional expense allowance of $€ 15$ for participating in the group discussion. The average age was 40.5 years old, with a range of $19-76$. Of the participants, $85 \%$ was female.

Since prior research (e.g. Netherlands Nutrition Centre/Motivaction based on consumer mentality profiles, 2015, and the results of food waste surveys by Netherlands Nutrition Centre / GfK, 2015) showed that single-person households, families with (young) children, and adolescents and young adults (in particular under the age of 25) waste more food on average than other groups, these respondents were selected to participate in the study. One third of the participants had a single-person household, one third a family with (young) children and one third of the participants was under the age of 25 .

\subsection{Products}

In consultation with the supervisory committee, 20 different product categories were selected for this study.

The products in this study are products with a long shelf life with a best before date, which are not on the Annex X list of the EC Directive 1169/2011 ${ }^{1}$ (and thus are already allowed to be sold to consumers without a date), supplemented by other products with a long shelf life relevant to the study. The list of products discarded most often by consumers at home was also consulted to this end (Netherlands Nutrition Centre - Consumer Food Waste Factsheet, 2014).

The products selected for the online task were the top 10 products thrown away by participants during the sorting task.

\footnotetext{
1 "on the provision of food information to consumers". Annex X concerns the 'Date of minimum durability, 'use by' date and date of freezing"
} 
Table 3. List of the products in the study

\begin{tabular}{|c|c|c|c|}
\hline & Product category & $\begin{array}{l}\text { Sorting } \\
\text { task }\end{array}$ & Online task \\
\hline 1 & Fish (canned) & $\mathrm{x}$ & $\mathrm{x}$ \\
\hline 2 & Drinks and soft drinks & $\mathrm{x}$ & \\
\hline 3 & (Dried) vegetables in package/bag & $\mathrm{x}$ & $\mathrm{x}$ \\
\hline 4 & Vegetables (canned) & $\mathrm{x}$ & $\mathrm{x}$ \\
\hline 5 & Vegetables (in glass) & $\mathrm{x}$ & $\mathrm{x}$ \\
\hline 6 & Honey & $\mathrm{x}$ & \\
\hline 7 & Coffee & $\mathrm{x}$ & \\
\hline 8 & Flour & $\mathrm{x}$ & $\mathrm{x}$ \\
\hline 9 & Packages of juice & $\mathrm{x}$ & $\mathrm{x}$ \\
\hline 10 & Pasta & $\mathrm{x}$ & \\
\hline 11 & Rice & $\mathrm{x}$ & \\
\hline 12 & Sauces & $\mathrm{x}$ & $\mathrm{x}$ \\
\hline 13 & Syrup & $\mathrm{x}$ & \\
\hline 14 & Soup & $\mathrm{x}$ & $\mathrm{x}$ \\
\hline 15 & Soup powder & $\mathrm{x}$ & $\mathrm{x}$ \\
\hline 16 & Treacle & $\mathrm{x}$ & \\
\hline 17 & Sugar & $\mathrm{x}$ & \\
\hline 18 & Tea & $\mathrm{x}$ & \\
\hline 19 & Tomato paste & $\mathrm{x}$ & $\mathrm{x}$ \\
\hline 20 & Salt & $\mathrm{x}$ & \\
\hline
\end{tabular}

All products used in this study were Premium brands. 


\section{Results}

\subsection{Sorting task}

Which products participants would throw away and which they would keep was tallied for all participants. Figure 4 depicts the results of all products added up. This figure shows that the products with an expired best before date were thrown away significantly more often than products without a date. Products without a date were thrown away 12\% less often than products with an expired best before date (39\%-27\%).

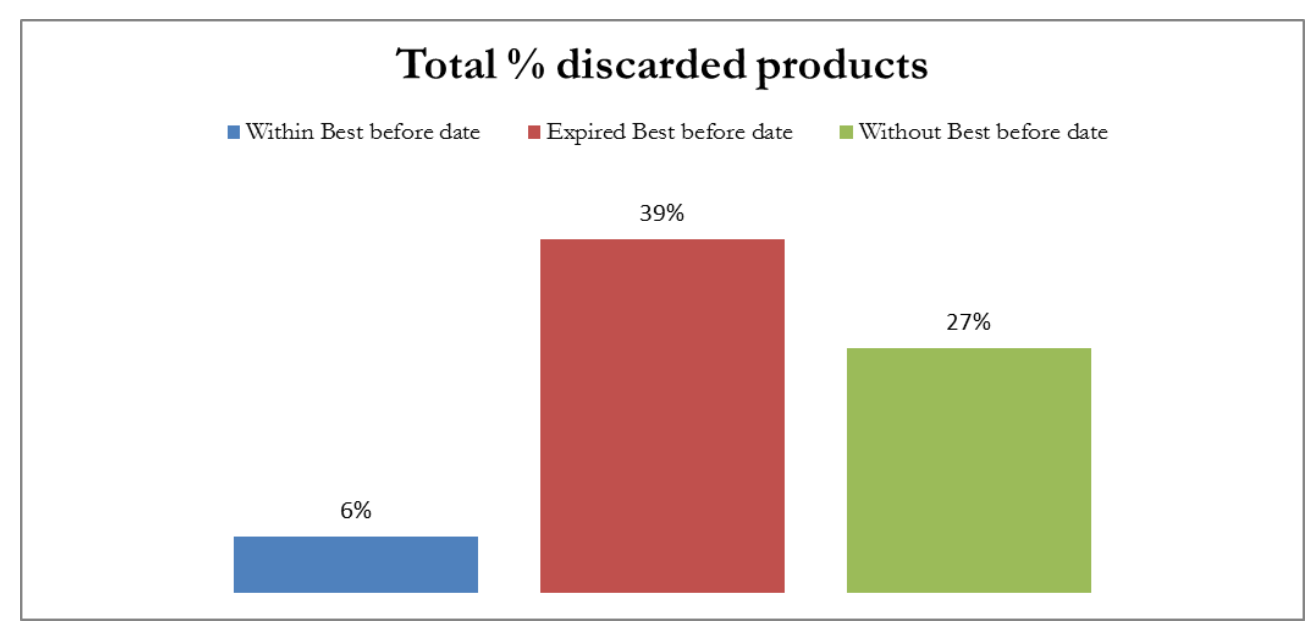

Figure 4. Total percentage of products discared during the sorting task

However, there are major differences between product categories. Table 4 shows that treacle and tomato paste are discarded 23\% less often when they have no date label. Packages of juice, however, are thrown away $5 \%$ more often if they do not have a date label. 
Table 4. Percentage of products discarded during the sorting task

\begin{tabular}{|c|c|c|c|c|c|}
\hline Category & $\begin{array}{l}\text { Expired } \\
\text { best } \\
\text { before } \\
\text { date }\end{array}$ & $\begin{array}{l}\text { Without } \\
\text { a best- } \\
\text { before } \\
\text { date }\end{array}$ & $\begin{array}{l}\mathrm{p}- \\
\text { value }\end{array}$ & significance & difference \\
\hline Treacle & $37 \%$ & $14 \%$ & 0.0001 & $* * *$ & $-23 \%$ \\
\hline Tomato paste & $50 \%$ & $27 \%$ & 0.0011 & $* *$ & $-23 \%$ \\
\hline Fish (canned) & $71 \%$ & $50 \%$ & 0.0009 & $* * *$ & $-21 \%$ \\
\hline Honey & $29 \%$ & $9 \%$ & 0.0002 & $* * *$ & $-20 \%$ \\
\hline $\begin{array}{l}\text { Vegetables } \\
\text { (canned) }\end{array}$ & $44 \%$ & $27 \%$ & 0.0035 & $* *$ & $-17 \%$ \\
\hline Soup & $66 \%$ & $51 \%$ & 0.0259 & $*$ & $-15 \%$ \\
\hline Soup powder & $48 \%$ & $34 \%$ & 0.0139 & $*$ & $-14 \%$ \\
\hline Flour & $43 \%$ & $29 \%$ & 0.0190 & $*$ & $-14 \%$ \\
\hline Pasta & $15 \%$ & $2 \%$ & 0.0055 & $* *$ & $-13 \%$ \\
\hline Rice & $22 \%$ & $9 \%$ & 0.0153 & $*$ & $-13 \%$ \\
\hline $\begin{array}{l}\text { Beans/vegetables } \\
\text { bag/package }\end{array}$ & $45 \%$ & $33 \%$ & 0.1093 & n.s. & $-13 \%$ \\
\hline Sugar & $19 \%$ & $8 \%$ & 0.0433 & $*$ & $-10 \%$ \\
\hline $\begin{array}{l}\text { Drinks and soft } \\
\text { drinks }\end{array}$ & $30 \%$ & $21 \%$ & 0.1698 & n.s. & $-9 \%$ \\
\hline Tea & $16 \%$ & $8 \%$ & 0.1213 & n.s. & $-8 \%$ \\
\hline Coffee & $27 \%$ & $20 \%$ & 0.2636 & n.s. & $-7 \%$ \\
\hline Syrup & $36 \%$ & $29 \%$ & 0.4047 & n.s. & $-7 \%$ \\
\hline Sauces & $52 \%$ & $47 \%$ & 0.4576 & n.s. & $-6 \%$ \\
\hline $\begin{array}{l}\text { Glass jars of } \\
\text { vegetables }\end{array}$ & $57 \%$ & $52 \%$ & 0.5224 & n.s. & $-5 \%$ \\
\hline Salt & $7 \%$ & $3 \%$ & 0.3711 & n.s. & $-3 \%$ \\
\hline Juice packages & $58 \%$ & $63 \%$ & 0.5708 & n.s. & $+5 \%$ \\
\hline Average & $39 \%$ & $27 \%$ & & & $-12 \%$ \\
\hline
\end{tabular}

\footnotetext{
*** = significant $99.9 \%$, p-value 0.001

** $=$ significant $95 \%$, p-value 0.05

$* \quad=$ significant $90 \%$, p-value 0.1

n.s. $=$ not significant
} 
Below is an example of how the percentages in Table 4 were calculated:

- Of the 86 participants 32 threw away the treacle if the best before date had expired. This is $37 \%$. $(32 / 86) * 100$.

- If the treacle did not carry a best before date, 12 participants discareded it. This is $14 \%$. $(12 / 86) * 100$.

- Therefore, the difference for the product category treacle is $23 \%(37 \%-14 \%)$.

The analyses for the other 19 categories were carried out in identical fashion. 
Figure 5 is a graphic depiction of the comparison on discarding behaviour by consumers of products without and with expired best before date labels. A number of significant differences were found between the different product categories.

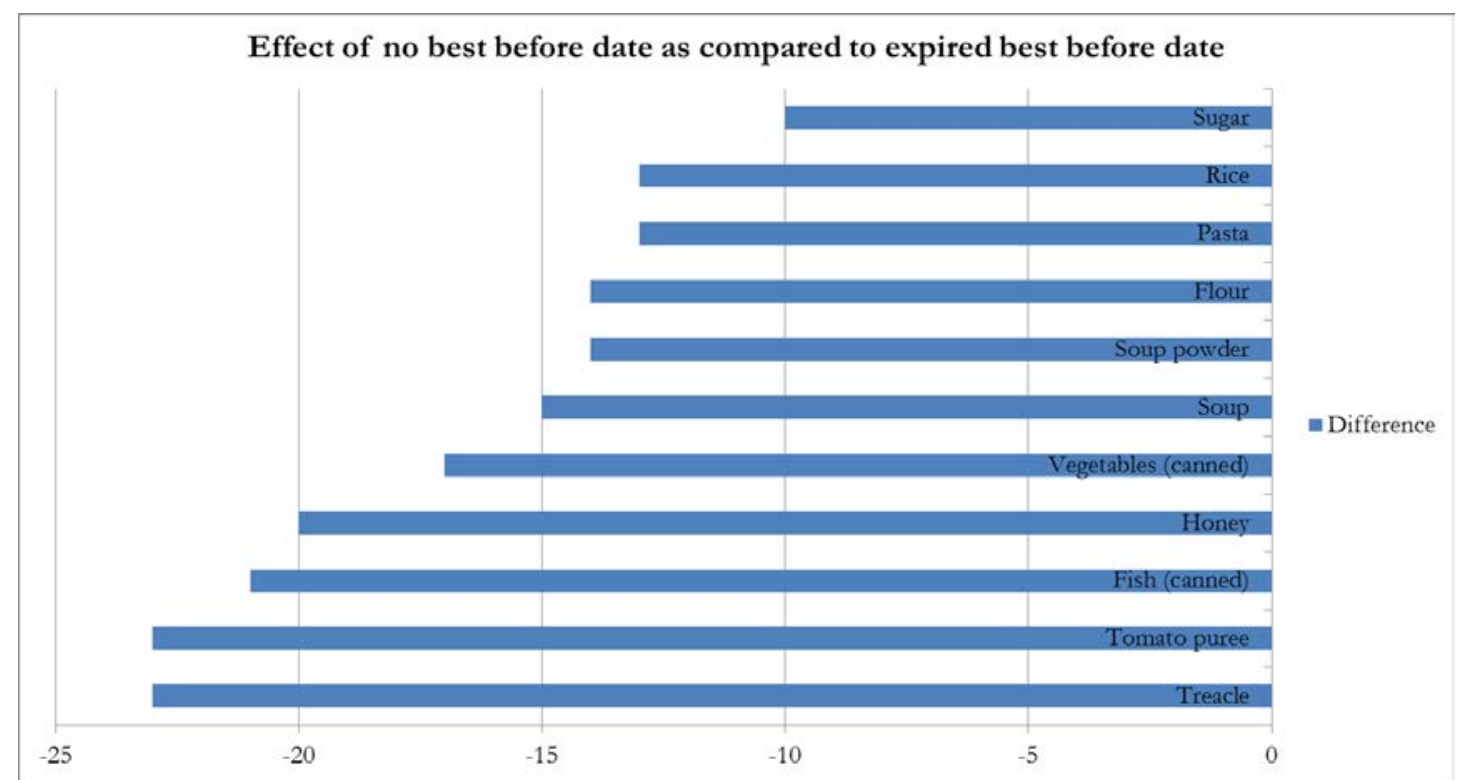

Figure 5 Effect of no best before date as compared to expired best before date 


\subsection{Online task}

Below the results of the online task are described. If the term 'Long shelf life' (without a date label) is shown on the packaging, $31 \%$ less is thrown away compared to the current terminology. This holds for all product categories. Also when the term 'Quality guaranteed until [date]' is used, less food is thrown away (-5\%) (effect found within the sauce category). The terms 'Produced on [date]' and 'At its best before [date]' lead to respondents tending to throw away products sooner. Figure 6 shows the percentage of products thrown away for each alternative term. The current term 'Best before [date]' is shown in red.

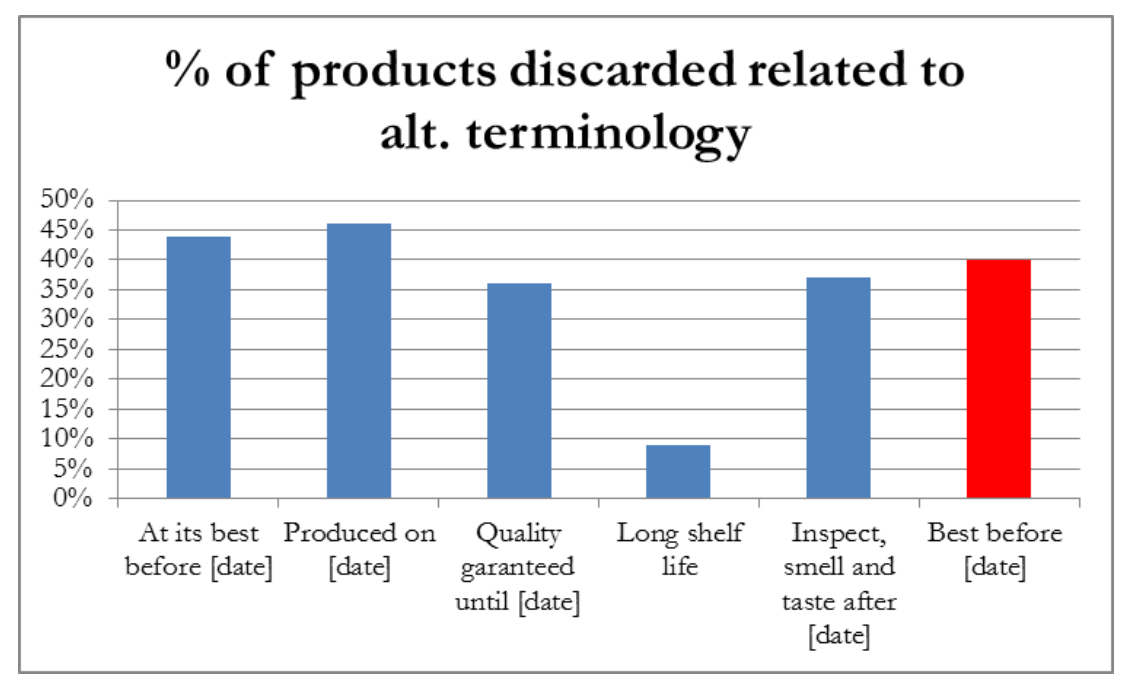

Figure 6. Number of products thrown away related to alternative terminology

Table 5 depicts the differences per alternative term as compared to the current term 'Best before [date]'.

Table 5. Effect of the alternative terms on the discarding behaviour of participants

\begin{tabular}{|l|l|l|l|}
\hline Alternative terminology & $\begin{array}{l}\text { Difference compared } \\
\text { to current date label } \\
\text { (best before [date]) }\end{array}$ & p-value & significance \\
\hline At its best before [date] & $+4 \%$ & 0.0447 & $*$ \\
\hline Produced on [date] & $+6 \%$ & 0.00285 & $* *$ \\
\hline Quality guaranteed until [date] & $-5 \%$ & 0.0116 & $*$ \\
\hline Long shelf life (without date) & $-31 \%$ & $<0.001$ & $* * *$ \\
\hline $\begin{array}{l}\text { Inspect, smell and taste after } \\
\text { [date] }\end{array}$ & $-3 \%$ & 0.1300 & n.s. \\
\hline
\end{tabular}


Below is an example of how the percentages in Table 5 were calculated:

- When the term 'Best before [date]' is used, $40 \%$ of the products are thrown away. If the term 'Produced on [date]' is used on the packaging, $46 \%$ of the products are thrown away. This is a difference of $6 \%(46 \%-40 \%)$.

All of the results presented above are based on the behaviour actually displayed by the participants if certain information was provided on a product. Asked which terminology the participants thought more appealing, different results were found. Respondents indicate that they find the terms 'Best before [date]' and 'Quality guaranteed until [date]' appealing, and that they find the terms 'Produced on [date]' and 'Long shelf life' to be unappealing terms.

How appealing respondents consider a term to be, does not necessarily seem to be related to the potential of the term to influence their behaviour (in this case reducing food waste). 


\subsection{Focus group discussion}

In this section the results of the focus group discussion are outlined. Only group results are given and no individual opinions are listed.

During the focus group discussion participants indicated that there are two main motives for discarding products with a long shelf life. Food safety was the most important motive, with taste coming in second place. Respondents are afraid of becoming ill from products with an expired best before date. This is particularly the case for products containing processed meat, fish or eggs. Products with a lower perceived sense of risk were flour, coffee, tea, rice, pasta, sugar, dried spices and herbs, and soft drinks.

Taste deterioration is mainly an issue with products that are not processed further before consumption, but are consumed straight out of the package.

How people subsequently decide whether they will throw something away is determined by three factors:

- Knowledge and attitude of the consumers themselves

- Packaging/storage method

- Product/ingredient

If someone has little knowledge on the duration of shelf life of a product, this will lead to extra insecurity resulting in a product being thrown away sooner. Respondents with a sufficient budget or ones with less affinity with environmental issues also tend to discard product more quickly. Products with vulnerable or wet ingredients are also thrown away more quickly. It was also found that products which require no further processing before consumption were sooner discarded.

\section{Quotes:}

'I'd rather spend two euros on a new product than become ill from it'

'I certainly won't serve my guests beer with a recently expired best before date. That would be embarrassing'

'I noticed that I wanted to know the facts, I have too little knowledge. And then I have to trust that manufacturer too'

'I heard on the news that rice can't really spoil' They should publicise that; then I would throw it away much less quickly'

'I consider sustainability to be important. If you throw something away, you waste it' 


\section{Alternative terminology}

When questioned about alternative terminology, the opinions of the participants were divided and there was no single term that clearly stood out.

The term 'Produced on [date]' was not found to be appealing because this term seems to imply that consumers have a lot of knowledge.

The same goes for the term 'Long shelf life'. This term also assumes consumers have a great deal of knowledge and is not very specific.

Although "At best if used before [date]' is a term that did not evoke a lot of aversion, it was not much of a favourite either.

The term 'Quality guaranteed until [date]' was appealing to some of the respondents. It creates certainty to a degree, but also raises the question for some of what will happen after the date. The term 'Inspect, smell and taste after [date]' led to the greatest differences of opinion among the respondents. People with a slightly higher degree of product knowledge liked the term. People with little product knowledge felt that it was a term that evoked a lot of uncertainty regarding potential danger, whether you were capable of smelling well and the fact that you wouldn't taste something you had doubts about.

In summary, respondents can be said to have a need for certainty and clarity, and would like any doubt to be resolved. The remaining question is whether this can be achieved with a term or whether communication perhaps should take place in another manner.

\section{$\underline{\text { No date label }}$}

The respondents were almost unanimous in the opinion that omitting a date label is undesirable. This leads to even less clarity, making people feel uncertain. No information at all is given which moreover makes the consumer fully responsible and implies that they are knowledgeable about how long a product can be kept. The respondents felt that they themselves did not have enough knowledge or did not consider themselves capable of judging the shelf life.

Although they could imagine that a date label does not need to be provided for certain dry products (e.g. sugar, rice, flour, tea), for the large majority of products it was considered desirable to have a clear indication. 


\section{Discussion}

This study was conducted with the participation of 86 Dutch consumers. The study indicates how consumers respond to changing the best before date on packaging and how this affects their discarding behaviour. Because this study involved a relatively small group of consumers selected from the Wageningen University and Research Centre's database ( Taste Panel), this may not be regarded as a representative sample reflecting 'the' Dutch consumer.

The experiments were conducted in a controlled environment. No research was conducted into discarding behaviour based on the number of kilograms ending up in waste bins, but concerned the selection behaviour related to products that respondents would discard in the experimental setting. Therefore, no statements can be made about how households would actually respond if the terminology were changed in practice. Whether consumers throw away a product will likely depend on many more factors than only the date marking on the packaging. Such factors have not been addressed in this study. Further research could concern the influence that various motives that consumers have for throwing away food products have on each other, and how this can be influenced.

The study does indicate what the possible changes could be if alternative terminology were adapted. In order to determine actual behaviour, various research methodologies can be used in a 'real-life' setting. In that case a study design can be chosen which yields quantitative results. The current study was limited to a qualitative investigation, which addressed the appeal of changing the current date marking terminology and potential changes in the intended discarding behaviour of consumers.

In this study the effect of various types of date marking terminology of products with a long shelf life on food waste was investigated. To this end, a certain selection was made. The impact of products with a long shelf life on food waste is relatively small compared to fresh products and leftovers from prepared meals. In order to reduce total food waste, these product categories will also have to be studied.

Finally, there is also the influence of national and European legislation. Some changes to food labels may not be permissible as yet. This fact needs to be addressed when an alternative term is implemented or date marking is omitted from product packaging.

This study has yielded valuable supplementary insights into the appeal of alternative terminology, and in any case has shown that from the consumer's perspective omitting the best before date on products with a long shelf life is not strictly desirable. 


\section{Conclusions}

This indicative study shows that products with a long shelf life are thrown away less often by respondents if they do not have a best before date on the packaging $(-12 \%$ on average). This percentage is the average for the 20 product categories used in this study.

The results regarding using alternative terminology show that respondents throw away 31\% less if the packaging carries the term 'Long shelf life' (without a specific date being mentioned). The term 'Quality guaranteed until [date]' also led to 5\% fewer products being thrown away. However, there were also alternative terms which led respondents to throw away more: 'Produced on $[\text { date }]^{\prime}(+6 \%)$ and 'At its best if used before [date]' (+4\%). The term 'Inspect, smell and taste after [date $]^{\prime}$ led to the same amount being thrown away as with the current term 'Best before [date]'.

Although it did lead to respondents throwing away less, they did indicate that they found the term 'Long shelf life' unappealing because it offers no clarity about the food safety and the quality of the product in question. This uncertainty turns out to have a significant influence on consumer discarding behaviour: Can I still safely consume this product? Will it taste good?

Both omitting date marking and introducing alternative terminology could contribute to reducing food waste in households. Introducing these measures in stages is recommended, since the study indicated that for some of the product groups being investigated (products such as sugar, rice, flour and tea), respondents did not experience such uncertainty. Using the term 'Long shelf life' on the packaging of these products seems promising. In addition, attention should be paid to changing the risk perception of consumers. There are various options, such as providing better consumer information, providing information on the product packaging (perhaps also with QR codes or smartphone applications). Exactly how this should be done will have to be shown in further research. 


\section{References}

Voedingscentrum en GfK - Temminghoff, M \& Damen, N., 2013. Voedselverspilling 1-meting.

Flash Eurobarometer 425, 2015. On food waste and date marking. Survey performed by TNS

Political and Social, commissioned by EC DG Sanco.

FAO, 2013. Food wastage footprint - impacts on natural resources.

Wageningen UR Food \& Biobased Research - Vollebregts et al. 2016. Monitor voedselverspilling update 2012-2014. 


\section{Appendix 1 Cover stories}

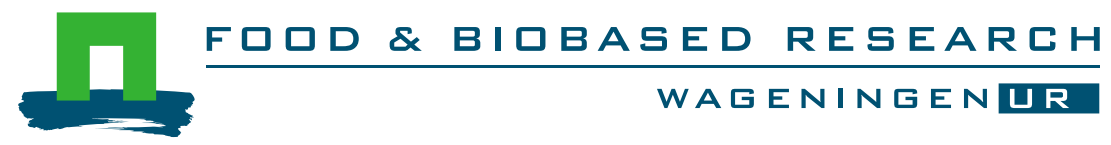

Cover story 1

Dear participant,

Thank you for agreeing to participate in this study.

You will shortly be visiting a close friend's home.

Your friend recently departed on a long trip, travelling the globe, and has decided to extend it. $\mathrm{He}$ has no idea when he will return. So he has asked you to empty out his kitchen cupboards entirely. You now have the job of inspecting the contents of the cupboards and dividing everything into two categories:

- Products to be thrown away because they are inedible

- Products to be kept to take home to consume yourself or to give away to someone else.

Put the products you want to discard in the bin bag or place them on it. Put the products you want to keep in the crate.

Please note that you should not open any packaging!

The packaging has date marking information on it. If the best before date is hidden under a sticker or tape or is crossed out, this is because the best before date for that product is unknown.

If you have any further questions, please let us know.

Good luck! 
Cover story 2

Dear participant,

Thank you for agreeing to participate in this study.

You will shortly be visiting your mother/grandmother's home.

Your mother/grandmother has recently been admitted to a care hotel and it is not yet clear when she will be returning home. So she has asked you to empty out her kitchen cupboards entirely. You now have the job of inspecting the contents of the cupboards and dividing everything into two categories:

- Products to be thrown away because they are inedible

- Products to be kept to take home to consume yourself or to give away to someone else.

Put the products you want to discard in the bin bag or place them on it. Put the products you want to keep in the crate.

Please note that you should not open any packaging!

The packaging has date marking information on it. If the best before date is hidden under a sticker or tape or is crossed out, this is because the best before date for that product is unknown.

If you have any further questions, please let us know.

Good luck! 


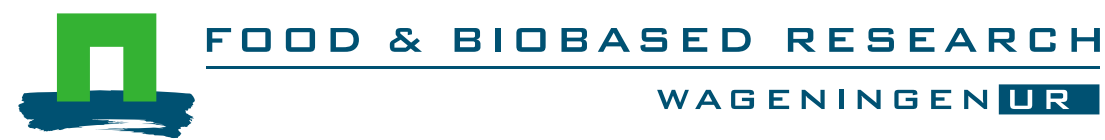

Cover story 3

Dear participant,

Thank you for agreeing to participate in this study.

You will shortly be visiting a close friend at their home.

Your friend will be departing on a trip travelling the world soon and has decided to rent out his place for six months. So the kitchen cupboards need to be emptied entirely. You may have anything in there, since he has no need for it while on holiday. You now have the job of inspecting the contents of the cupboards and dividing everything into two categories:

- Products to be thrown away because they are inedible

- Products to be kept to take home to consume yourself or to give away to someone else.

Put the products you want to discard in the bin bag or place them on it. Put the products you want to keep in the crate.

Please note that you should not open any packaging!

The packaging has date marking information on it. If the best before date is hidden under a sticker or tape or is crossed out, this is because the best before date for that product is unknown.

If you have any further questions, please let us know.

Good luck!

26 (C) Wageningen Food \& Biobased Research, an institute within the legal entity Stichting Wageningen Research (Wageningen Research Foundation) 